\title{
RESEARCH
}

Open Access

\section{Effects of EFNA1 on cell phenotype and prognosis of esophageal carcinoma}

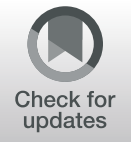

Yongqiang Zhang, Jinning Zhang, Guanlong Pan, Tianhao Guan, Changhao Zhang, An Hao, Yan Li and Hai Ren*

\begin{abstract}
Background: To investigate the expression and clinical significance of EFNA1 in broad-spectrum tumors, and to evaluate its relationship with prognosis and biological functions of esophageal carcinoma (ESCA).

Methods: EFNA1 expression in various cancers was analyzed according to the data in the TCGA database. The clinical data were integrated, to analyze the relationship with ESCA clinical parameters and prognosis, and EFNA1 expression in ESCA tissue samples was detected by immunohistochemistry (IHC). Based on bioinformatics, the functional background of EFNA1 overexpression was analyzed. EFNA1 knockout cell model was established by EFNA1-shRNA transfecting ESCA cells, and the effect of knocking down EFNA1 on the proliferation of ESCA cells was detected by MTT.
\end{abstract}

Results: Among 7563 samples from TCGA, the EFNA1 gene highly expressed in 15 samples with common cancers and endangered the prognosis of patients with tumors. Its overexpression in ESCA and its influence on the prognosis were most significant. EFNA1 expression in 80 samples with ESCA and their paired samples was tested by $I H C$ to verify its high expression (paired t test, $P<0.001$ ) in ESCA tissues. It was found that EFNA1 expression was related to clinical factors (TNM staging, $P=0.031$; lymph node metastasis, $P=0.043$; infiltration, $P=0.016$ ). Meanwhile, EFNA1 was found to be an independent risk factor based on the COX multi-factor analysis. And to further explore the importance of EFNA1 in tumors, EC-9706 and ECA109 cells were screened from 8 ESCA-related cell lines to build EFNA1 knockdown cell models. The results showed that EFNA1 knockdown significantly inhibited the proliferation of tumor cells $(P<0.05)$. In terms of molecular mechanism, EFNA1 related genes were significantly enriched in the proliferative pathway according to the pathway enrichment analysis. It was found that knocking down EFNA1 did inhibit cell proliferation based on cell experiments.

Conclusions: EFNA1 overexpression in ESCA tissue is related to the prognosis of patients. Knocking down EFNA1 can significantly inhibit the proliferation of ESCA cells.

Keywords: EFNA1, Esophageal carcinoma, Prognosis, Cell proliferation

\footnotetext{
*Correspondence: renhai20210128@126.com

Ward 2, Department of Cardiothoracic Surgery, The Third Affiliated Hospital of Qiqihar Medical College, No. 27, Taishun Street, Tiefeng District, Qiqihar 161000, Heilongjiang Province, China
}

(c) The Author(s). 2021 Open Access This article is licensed under a Creative Commons Attribution 4.0 International License, which permits use, sharing, adaptation, distribution and reproduction in any medium or format, as long as you give appropriate credit to the original author(s) and the source, provide a link to the Creative Commons licence, and indicate if changes were made. The images or other third party material in this article are included in the article's Creative Commons licence, unless indicated otherwise in a credit line to the material. If material is not included in the article's Creative Commons licence and your intended use is not permitted by statutory regulation or exceeds the permitted use, you will need to obtain permission directly from the copyright holder. To view a copy of this licence, visit http://creativecommons.org/licenses/by/4.0/ The Creative Commons Public Domain Dedication waiver (http://creativecommons.org/publicdomain/zero/1.0/) applies to the data made available in this article, unless otherwise stated in a credit line to the data. 


\section{Background}

Esophageal carcinoma (ESCA) is the eighth most common cancer and the sixth most common cause of cancer death in the world [1]. As one of the common malignant tumors, the number of new and dead cases of ESCA ranked 7th and 6th among the tumors according to the Global Cancer Society Report 2018 [2]. Currently, ESCA has high incidence in China, with higher mortality and morbidity than the global average. In China, the occurrence of ESCA is geographically clustered, which may be related to living conditions, dietary habits, and genetic susceptibility [3]. The early symptoms of ESCA are not typical. Progressive dysphagia is the main complaint of most patients with ESCA, which is often the advanced stage of the disease [4]. At present, surgery is the first choice for ESCA, but the tumor recurrence rate is high after surgery, which is easy to be distant metastasis, with poor long-term effect. It will also cause skeletal muscle loss and affect patients' quality of life [5]. Therefore, it is of great significance to find biomarkers for early ESCA screening and to predict the targets for the prognosis of ESCA.

Eph (erythropoietin-producing hepatoma) receptor is the largest receptor tyrosine kinase (RTK), which can be divided into two subcategories according to sequence homology, including EphA1-10 and EphB1-6 [6]. EFNs (ephrins) is a ligand for Eph receptor which can be divided into two subcategories according to its connection with the membrane, among which, EFNAs (EFNA1-5) is fixed to the membrane by glycosyl-phosphatidyl inositol (GPI), while EFNBs (EFNB1-3) is immobilized through the transmembrane protein domain [7]. EFNA1 has about $30-40 \%$ similarity to other EFNs, which can bind to multiple EPHA receptors (EPHA1-5) [8]. Among which, EphA2 is the most common receptor of EFNA1. The binding of ligand EFNA1 to receptor EphA2 can promote phosphorylation, which in turn regulates cell growth, differentiation, apoptosis, and angiogenesis, so as to be involved in tumorigenesis and metastasis $[9,10]$. Literature have documented that EFNA1 extensively involved in tumorigenesis by influencing tumor angiogenesis $[11,12]$, malignant cell events $[13,14]$, and invasiveness [15]. Its expression is up-regulated in many cancers (e.g., gastric cancer [16], colorectal cancer [17], renal cancer [18]), which is closely related to the prognosis of many cancers $[19,20]$. The study by De Robertis et al. has also found that EFNA1 may become a prognostic marker for colorectal cancer [21]. Current studies have found EFNA1 to be associated with the prognosis and progression of many tumors, including digestive system tumors. However, EFNA1 expression in ESCA and its relationship with the prognosis of patients, as well as its role in tumor progression, remain unclear and need further study.
Therefore, this study first systematically analyzed EFNA1 in a variety of tumors and found that its high expression in ESCA is the most significant and is related to the prognosis in ESCA. We further explored the relationship between EFNA1 and the proliferation of ESCA cells at the cell level, providing basic theoretical basis for studying the pathogenesis of ESCA and prognosis evaluation of patients.

\section{Materials and methods}

\section{Data mining}

The mRNA expression spectrum and clinical data of patients with common tumors and controls were downloaded from the Cancer Genome Map TCGA (https:// tcga-data.nci.nih.gov/tcga/) Database. Data were preprocessed by sorting, ID converting, filtering, merging, correcting the data from different expression spectrum and extracting clinical data. EFNA1 expression in each tumor was analyzed with the "meta" software package of R software (version 3.6.3), and the influence of EFNA1 expression on the prognosis of each tumor was analyzed with the "survival" software package of $\mathrm{R}$ software. Through univariate COX analysis, the clinical data and EFNA1 expression were analyzed, as well as the scanned parameters with $P<0.02$. In order to predict the potential functions of EFNA1, the differentially expressed genes (DEGs) of patients with ESCA were identifies in the TCGA data with the edgeR package in the $\mathrm{R}$ software that were divided into high expression group and low expression group. $|\log 2 \mathrm{FC}|>1$ and calibration $P<0.05$ were taken as cutoff values for DEGs screening. After that, DEGs were analyzed with GO terms to predict their functions. The pathway with $P<0.05$ was considered statistically significant. STRING revealed that the interaction between these DEGs was visualized by the protein interaction (PPI) network.

\section{Clinical samples}

The pathological specimens surgically removed from patients in the Department of Cardiothoracic Surgery, the Third Affiliated Hospital of Qiqihar Medical University, from December 2014 to December 2020, were selected as specimens for the remaining paraffin sections after pathological examination. Inclusion criteria are as follows: (1) patients undergoing surgical resection in the Thoracic Surgery Department of our hospital, (2) patients with pathology diagnosed as ESCA, and (3) patients with primary tumor foci. Exclusion criteria are follows: (1) patients who have received preoperative radiotherapy and chemotherapy, (2) patients received second operation, and (3) patients with severe cardiopulmonary and other basic diseases. The adjacent tissues were taken $2-3 \mathrm{~cm}$ away from the tumor and histopathologically confirmed to be non-cancerous tissues. 
Each specimen was stored in liquid nitrogen $15 \mathrm{~min}$ in vitro for subsequent experiments. This study has been approved by the Ethics Committee in our hospital.

\section{Immunohistochemical (IHC) and pathological score} Paraffin sections were baked at $60^{\circ} \mathrm{C}$ for $2 \mathrm{~h}$, dewaxed with xylene (Shanghai Sangon, China), as well as gradient ethanol dehydration, and were washed by PBS, which were then repaired with high pressure antigen for $10 \mathrm{~min}$, and washed PBS again. The sections were soaked in $3 \% \mathrm{H}_{2} \mathrm{O}_{2}$ for $10 \mathrm{~min}$ to block exogenous peroxidase activity, closed with goat serum for $10 \mathrm{~min}$ (at room temperature), and then were incubated with added rabbit anti-human EFNA1 antibody (ab238505, Abcam, USA, $1: 100)$ at $4{ }^{\circ} \mathrm{C}$ overnight. The above sections were incubated with sheep anti-rabbit II (6926-100, Emmett Technology, China, 1:1000) at room temperature for 20 min and colored with added DAB (Zhongshan Jinqiao, Beijing) for $3 \mathrm{~min}$. Hematoxylin (Shanghai Sangon, China) was added for re-dying for $2 \mathrm{~min}$, with gradient ethanol for dehydration and resinene for sealing, which was placed under the microscope (Olympus, Japan) for observation.

The immunopathology score was performed by 2 senior pathology physicians in our hospital, and the total result was given according to the total score of the product of dyeing area and intensity. Dyeing area: $<10 \%(0$ point), $10-49 \%$ (1 point), $50-75 \%$ ( 2 points), $>75 \%$ (3 points); Dyeing intensity: uncolored (0 point), pale yellow (1 point), brown ( 2 points), dark brown (3 points), the total score $\geq 4$ represents high expression, and the total score $<4$ represents low expression.

\section{Cell culture}

Human esophageal carcinoma cell lines (EC-9706, ECA109, KYSE140, KYSE510, TE-10, TE-1, KYSE70) and human normal esophageal epithelial cell line HEEC were purchased from the Cell Bank of the Chinese Academy of Sciences. The cell DMEM (Corning, USA) was cultured with culture medium, with $10 \%$ fetal bovine serum (Thermo, USA) and $1 \%$ penicillin (Corning, USA). Conditions of culture: The cells were cultured in a constant temperature incubator at $37{ }^{\circ} \mathrm{C}$ and $5 \% \mathrm{CO}_{2}$.

\section{Real-time fluorescence qRT-PCR experiment}

RNA was extracted with Trizol method (15596026, Invitrogen, USA), which was then retranscripted as cDNA with TaKaRa Mini BEST FFPE DNA Extraction kit (RR047A, TaKaRa, Japan). Sampling was performed with SYBR Premix EX Taq kit (RR420A, Takara), which was amplified with ABI Step One Plus TM reaction apparatus (USA). Taking GAPDH as the internal reference gene, reaction system: SYBR Mix $9 \mu \mathrm{L}$, forward primer $0.5 \mu \mathrm{L}$, reverse primer $0.5 \mu \mathrm{L}$, cDNA $2 \mu \mathrm{L}$, RNase Free
dH2O $8 \mu \mathrm{L}$, reaction conditions: at $95^{\circ} \mathrm{C}$ for $10 \mathrm{~min}$, at $95^{\circ} \mathrm{C}$ for $15 \mathrm{~s}$, at $60^{\circ} \mathrm{C}$ for $1 \mathrm{~min}$, for 40 cycles. The $20 \mu \mathrm{L}$ reaction system was taken for RT-PCR. The target gene (EFNA1) and the internal reference gene (GAPDH) were amplified under the same reaction conditions, the relative expression of target gene was analyzed with $2^{-\Delta \Delta C t}$ (Table 1).

\section{Western blot}

The total cell protein was extracted, and then was detected with BCA method (Beyotime, China) for protein concentrations. After preparing the glue, the protein was isolated with SDS-PAGE electrophoresis. With transfer electrophoresis device, the protein was transferred to PVDF membrane (Millipore, USA) by wet transfer method at $4{ }^{\circ} \mathrm{C}$, under constant current of $300 \mathrm{~mA}$ for $90 \mathrm{~min}$, and sealed with TBST solution containing $5 \% \mathrm{BSA}$ at room temperature for $1 \mathrm{~h}$. Rabbit anti-human EFNA1 antibody (AB124911, abcam, 1:1000), rabbit anti-human CDK2 antibody (AB182858, abcam, 1:2000), rabbit anti-human cyclInd antibody (AB32503, abcam, 1: 1000), and rabbit anti-human cycline antibody (AB13847, abcam, 1:500) were added for incubation at $4{ }^{\circ} \mathrm{C}$ overnight, which were reacted with corresponding secondary antibodies (sheep anti-rabbit IgG, SantaCruz, SC-2004, USA, 1:2000). The bands of antigen-antibody binding region were detected with chemiluminescence method and analyzed by ImageJ software.

\section{Cellular transfection}

EFNA1-shRNA1 (5'CCGCGTCTTCACTGCAACG3') and EFNA1-shRNA2 (5'CTAGCAGAGATGACAATG3') were purchased from Genechem Company (Shanghai, China). Cells were inoculated on the 6-well plates (Corning, USA) and cultured to a fusion of 50 $70 \%$. According to the instructions of Lipofectamine 3000 Transfection kit (Invitrogen, USA), $10 \mu \mathrm{L}$ transfection reagent was diluted with $250 \mu \mathrm{L}$ serum-free medium, added into each hole of culture plates, and incubated for $4 \mathrm{~h}$ for subsequent experiments. The transfected EFNA1-shRNA was grouped into the EFNA1shRNA group, and the transfected blank plasmid was grouped into the negative control $(\mathrm{NC})$ group.

Table 1 Primer sequence list

\begin{tabular}{ll}
\hline Primer name & Primer sequence \\
\hline EFNA1 & 5'-CCGCTCATCGTGCAACCTG -3' (Forward) \\
& 5'-ATAAGAAGGCATCAGATCG-3' (Reverse) \\
GAPDH & 5'-TCCTTCAGCTTCCACGAG-3' (Forward) \\
& 5'-TCCTTCAGCTTCCACGAG-3' (Reverse) \\
\hline
\end{tabular}




\section{MTT detection}

After transfecting for $36 \mathrm{~h}$, the cells were inoculated in the 96-well plates at $5 \times 10^{3}$ cells/hole. After inoculation for $1,2,3,4$, and 5 days, $20 \mu \mathrm{L}$ MTT solution was added to each hole and incubated for $4 \mathrm{~h}$, the OD value was measured at $490 \mathrm{~nm}$ wavelength, and the cell growth curve was drawn.

\section{Statistical analysis}

The experiment was performed with SPSS 24.0 (SPSS, Chicago, USA) software for 3 times. Measurement data materials were processed with paired sample $t$ test and ANOVA. Counting data were compared with $x^{2}$ test. $\alpha=$ 0.05 was taken as the test standard, and $P<0.05$ was defined as that the difference was statistically significant.

\section{Results}

\section{EFNA1 expression in tumor tissues and its clinical} significance

To investigate EFNA1 gene expression in tumors, the research group systematically analyzed 15 common tumors in the TCGA database (control samples >10). In a comparison of 6872 tumors and 691 control tissues, EFNA1 gene was found to overexpress in most tumor tissues, especially in ESCA (Fig. 1A). After further integrating the EFNA1 gene expression and clinical data of 6872 patients, it was also found that the prognosis of patients with tumors was aggravated by EFNA1 gene overexpression, especially in patients with ESCA after screening (Fig. 1B).

\section{EFNA1 expression in ESCA clinical specimens}

In order to verify EFNA1 expression in ESCA tissues, we collected 80 pairs of ESCA tissues and adjacent control tissues from ESCA patients aged 47-79, including 41 males and 39 females. The intensity of EFNA1 expression in the samples was detected with IHC test, showing that EFNA1 expression in cancer tissues was significantly higher than that in adjacent tissues (paired $t$ test, $P<0.001$ ) (Fig. 2A, B), which was consistent with ESCA in TCGA (182 tumors and 286 normal tissues), and mRNA levels of EFNA1 were significantly higher in cancer tissues than those in normal tissues $(P<0.05)$ (Fig. 2C).

Clinical data from patients with ESCA were further collected, to analyze the relationship between EFNA1 expression and ESCA clinical parameters, which showed that EFNA1 expression was associated with TNM staging $(P=0.021)$, lymph node metastasis $(P=0.043)$, and invasion depth $(P=0.024)$ (Fig. 3A-C, supplementary table 1 ). Kaplan-Meier analysis of the relationship between EFNA1 expression and the prognosis of patients with ESCA showed that the obviously shorter overall survival rate was significantly associated with high EFNA1 expression $(P=0.0021)$ (Fig. 3D). The relationship between survival time and ESCA clinical

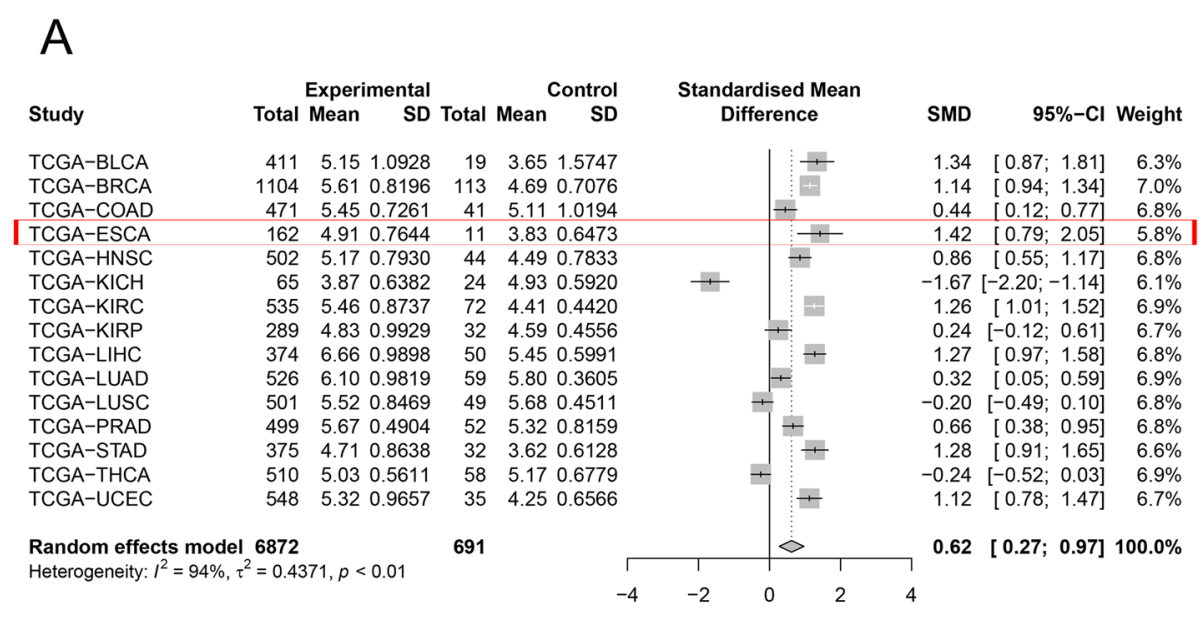

B

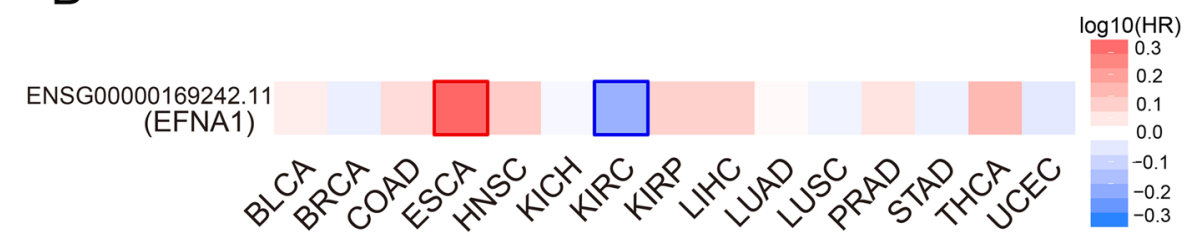

Fig. 1 EFNA1 expression in tumor tissue and its clinical significance. A Forest map of EFNA1 in 15 common cancers in TCGA. B The survival analysis of EFNA1 prognostic impact on multiple tumor patients, which was the most significant in ESCA 

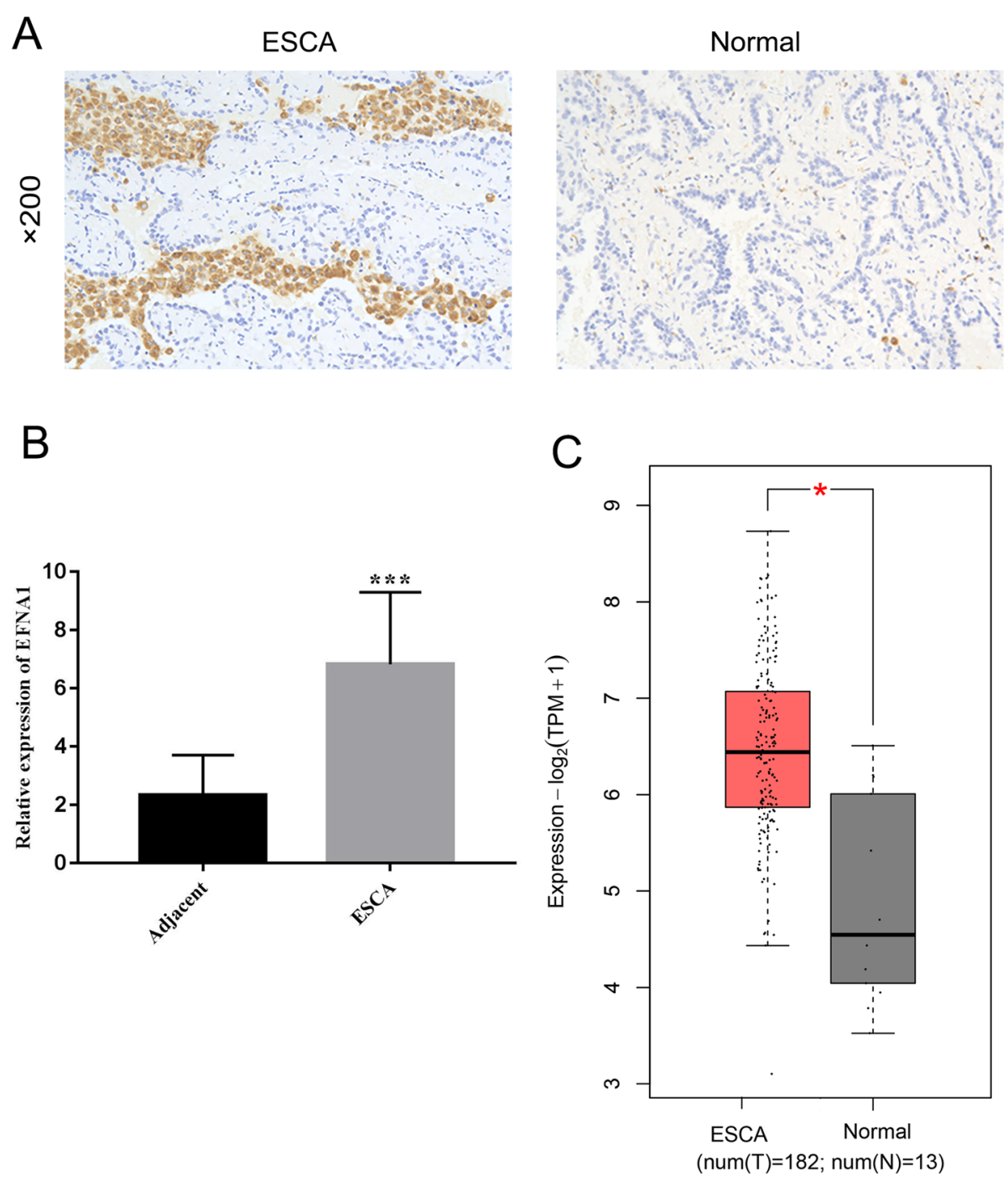

Fig. 2 EFNA1 expression in ESCA clinical specimens. A, B $1 \mathrm{HC}$ detection of EFNA1 expression in ESCA clinical samples. C EFNA1 expression in ESCA and 35 normal tissues, ${ }^{*} P<0.05$, ${ }^{*} P<0.01$, and ${ }^{*}{ }^{*} P<0.001$

parameters and EFNA1 expression was further analyzed. In the Cox univariate analysis, age $(P=0.037)$, TNM staging $(P=0.031)$, degree of invasion $(P=0.016)$, and EFNA1 $(P=0.011)$ were associated with the prognosis of patients with ESCA. The results of Cox multivariate analysis showed that only the degree of infiltration $(P=$ $0.041)$ and EFNA1 expression $(P=0.022)$ had independent significance (Table 2). We concluded that EFNA1 protein expression has been confirmed to be predictive to poor survival in patients with ESCA, which might be a good target for esophageal carcinoma therapy.

\section{EFNA1 expression in ESCA cells}

To verify the importance of EFNA1 to tumor cells, 7 ESCA cell lines (EC-9706, ECA109, KYSE140, KYSE510, TE-10, TE-1, KYSE70) and 1 human normal esophageal epithelial cell (HEEC) were selected. The expression of
EFNA1 mRNA and proteins was detected with qRTPCR and western blot methods at the cellular level. The result showed that the expression of EFNA1 mRNA and protein was significantly higher in cancer cells than those in normal cells $(P<0.001)$ (Fig. 4A, B). The expression was the most significant in EC-9706 cell line, and the lowest in ECA109 cell line compared with that of other ESCA cell lines. EC-9706 and ECA109 cell lines were selected for subsequent experiments.

The EFNA1 low-expression ESCA cell model was built with EFNA1-shRNA, and the transfection efficiency was detected with qRT-PCR. The result showed that in EC9706 and ECA109 cells, EFNA1 expression significantly decreased after EFNA1-shRNA transfection, especially in EFNA1-shRNA 1 group, compared with NC group $(P<$ 0.05) (Fig. 4C, D). EFNA1-shRNA 1 model was selected for subsequent experiments. 


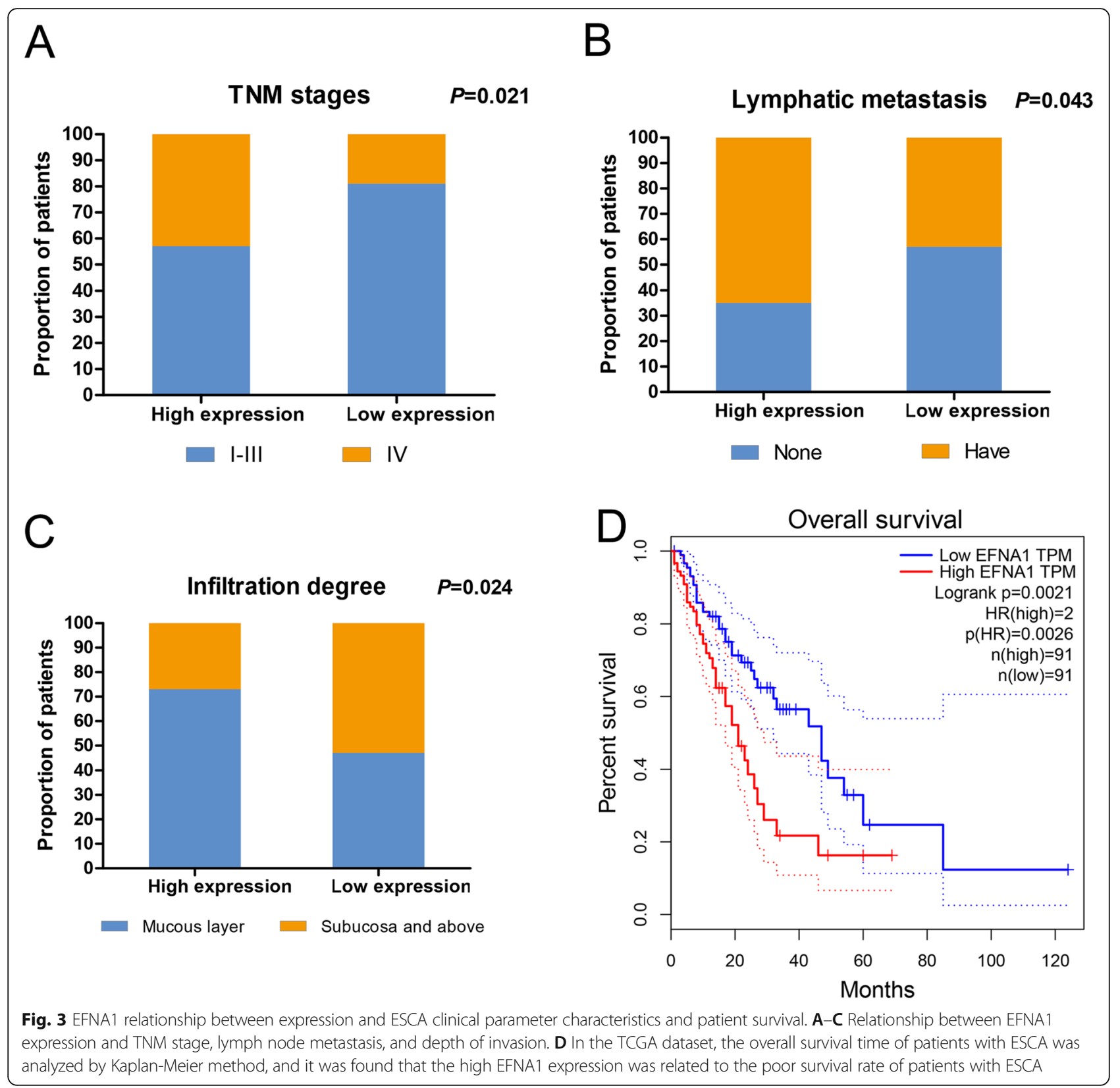

Table 2 Analysis of Cox univariate analysis and multivariate analysis affecting survival time of patients with ESCA

\begin{tabular}{|c|c|c|c|c|c|c|}
\hline \multirow[t]{2}{*}{ Parameters } & \multicolumn{3}{|c|}{ Cox univariate analysis } & \multicolumn{3}{|c|}{ Cox multivariate analysis } \\
\hline & HR & $\mathrm{Cl} 95 \%$ & $P$ value & $\overline{H R}$ & Cl $95 \%$ & $P$ value \\
\hline Age & 1.736 & $1.120-3.214$ & 0.037 & - & - & - \\
\hline Gender & 0.7980 & $0.291-1.853$ & 0.187 & - & - & - \\
\hline Tumor diameter & 0.575 & $0.258-1.786$ & 0.423 & - & - & - \\
\hline TNM staging & 2.035 & $1.417-3.676$ & 0.031 & - & - & - \\
\hline Lymph node metastasis & 0.532 & $0.346-1.562=$ & 0.412 & - & - & - \\
\hline Infiltration degree & 2.211 & $1.404-3.782$ & 0.016 & 1.828 & $1.142-3.147$ & 0.041 \\
\hline Degree of differentiation & 0.657 & $0.649-1.978$ & 0.215 & - & - & - \\
\hline EFNA1 expression & 2.335 & $1.301-4.926$ & 0.011 & 2.135 & $1.236-3.648$ & 0.022 \\
\hline
\end{tabular}




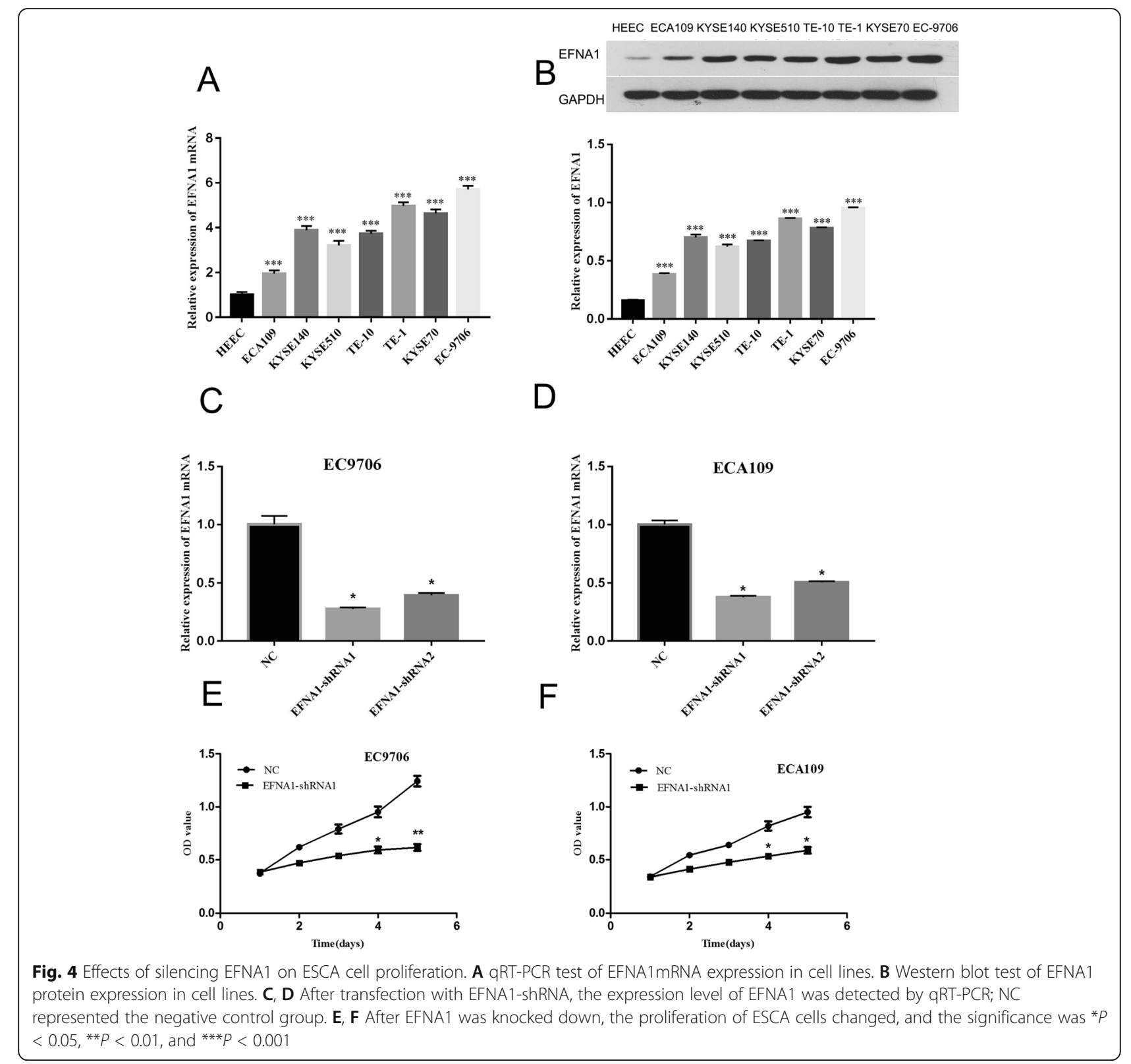

The findings in the MTT detection showed that, in EC-9706 and ECA109 cells, the cell proliferation was significantly decreased in EFNA1-shRNA1 group compared with NC group $(P<0.01, P<0.05)$ (Fig. 4E, F).

\section{EFNA1 molecular mechanism affecting ESCA cell proliferation}

To explore the molecular mechanism of EFNA1 affecting ESCA cell proliferation, the patient cohort was divided by EFNA1 median expression. A total of 283 differential genes were screened with "edgeR" of the $\mathrm{R}$ package as shown in the volcanic map of Fig. 5A, including 192 upregulated and 91 downgraded. Then, the PPI network diagram of EFNA1 related genes was constructed by String
(Fig. 5B), and it was found that EFNA1 related genes have complex protein interaction networks. GO enrichment analysis of DAVID pair and EFNA1-related genes showed that the main enrichment pathways were GO0045926: negative growth regulation, GO0031536: positive regulation of mitosis, GO0008284: positive regulation of cell proliferation, etc. (Fig. 5C), which was consistent with the results obtained from the above cell proliferation experiments.

\section{Discussion}

EFNA1 genes are also called B61, ECKLG, EFL1, EPLG1, GMAN, LERK-1, LERK1, and TNFAIP4, which are located on human chromosome 1 and encode EPH family 


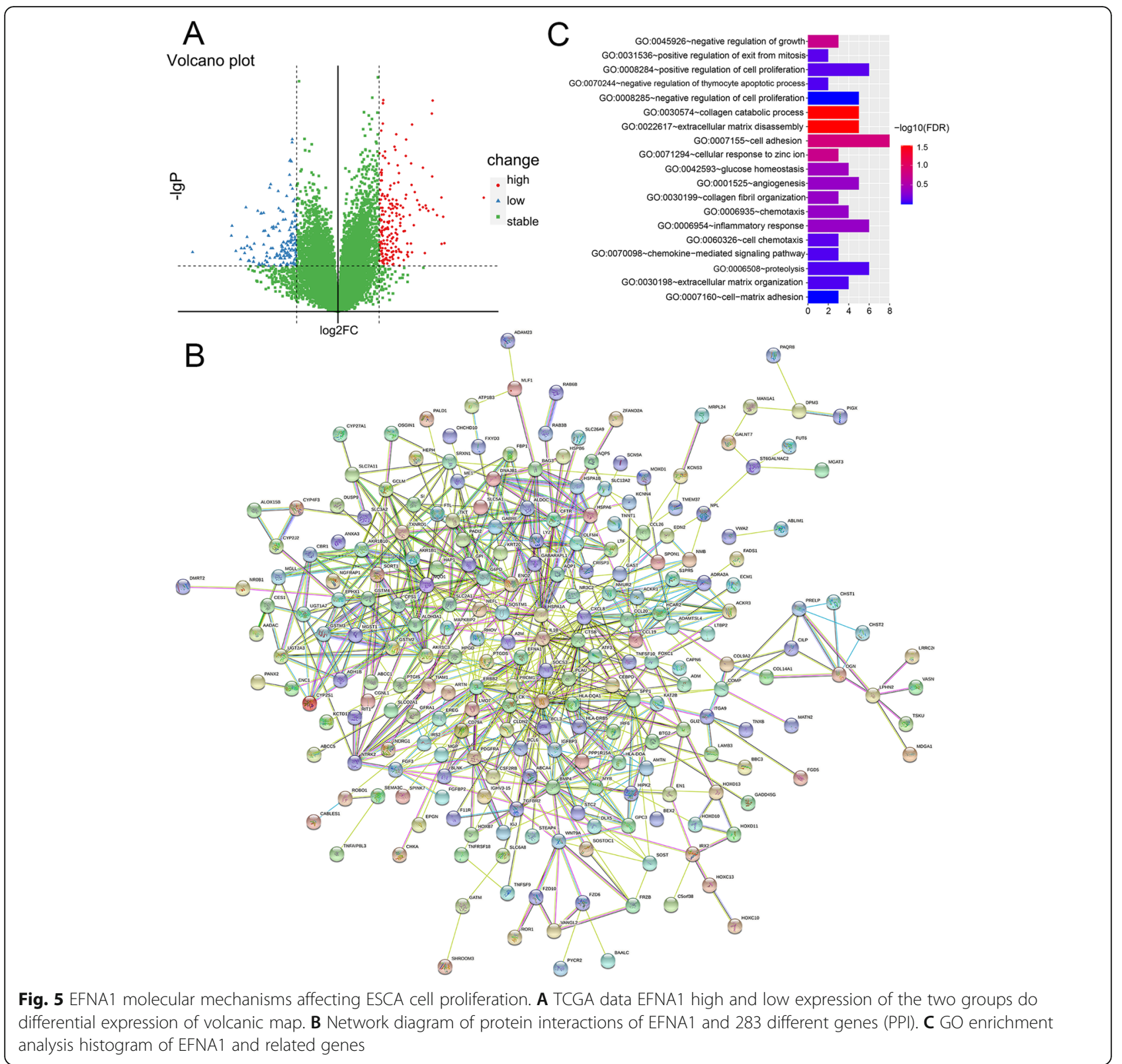

members. Wada et al. studied and reported that EFNA1 can predict the recurrence risk of patients with radical resection of liver cancer, which may become a prognostic marker [22], and some studies have found that it may be related to the prognosis of cervical cancer [23]. Studies have confirmed that EFNA1 may be associated with the prognosis of colorectal cancer, and single nucleotide polymorphism is the main factor leading to genetic susceptibility to tumors. However, Simonian et al. studied and found that there is no significant correlation between the re12904 of polymorphic loci in EFNA1 genes and the susceptibility to colorectal cancer, which may be related to specific populations [24].
Through the analysis of the related data of 15 tumors in the TCGA database, we found that EFNA1 overexpressed in a variety of tumors, especially in ESCA. Further integration analysis indicates that EFNA1 gene overexpression worsened the prognosis of patients with cancers, with the greatest impact on the prognosis of patients with ESCA. Our immunohistochemical results suggest that EFNA1 protein expression in tissues with ESCA is significantly higher than that in adjacent normal tissues, with statistically significant differences $(P<0.001)$. And EFNA1 expression is associated with lymph node metastasis $(P=$ $0.043)$, TNM staging $(P=0.021)$, and degree of invasion $(P=0.024)$, respectively. Tumor invasion is associated 
with ESCA staging; patients with ESCA with lesions confined to the mucosa have a better prognosis, suggesting that tumors with highly expressed EFNA1 may have a higher malignant biological potential. Excessive proliferation of tumor cells can lead to lymph node metastasis; tumors of upper esophagus are also prone to have lymph node metastasis [25]. This study found that EFNA1 is associated with lymph node metastasis, suggesting that high EFNA1 expression may affect the proliferation and metastasis of ESCA, and early metastasis is also one of the common causes for failure of anticancer therapy in clinical practice and an important factor affecting the prognosis of tumor patients. Thus, upregulation of EFNA1 expression may affect the prognosis of patients with ESCA. Our study showed that EFNA1 protein expression $(P=0.011)$ was significantly associated with shorter survival in patients with ESCA, except for age $(P=0.037)$, TNM staging $(P=$ $0.031)$, and degree of invasion $(P=0.016)$ in univariate analysis. Nevertheless, when COX multivariate analysis was applied, only the degree of infiltration $(P=0.041)$ and EFNA1 protein expression $(P=0.022)$ remained significantly associated with poor overall survival. At present, the main preferred treatment for ESCA is surgery, but postoperative tumor recurrence rate is high. The above results show that EFNA1, as an oncogene, may affect the prognosis of patients with ESCA, suggesting the poor prognosis. EFNA1 may be an effective index to evaluate the prognosis and recurrence of patients with ESCA.

Early detection and progression assessment of esophageal carcinoma require new biomarkers. The early symptoms of ESCA are atypical. Most of the patients with ESCA have progressive dysphagia as the main complaint, which is often the late stage of the disease. EFNA1 is a secreted protein of vascular endothelial cells [26], which highly expresses in ESCA, suggesting that it may be an effective marker for early diagnosis and screening of ESCA.

There is research evidence that EFNA1 is regulatory molecules for many malignant tumors, for example, EFNA1 induces miR-302b expression in malignant mesothelioma (MM) cells and inhibit the growth of tumor spheres by inducing apoptosis [14]. EFNA1 inhibits the proliferation of tumor cells in NSCLC by increasing the expression of tumor suppressor gene $\mathrm{cdx}-2$ [27]. The study of Zhuo et al. found that knocking out EFNA1 can weaken the invasiveness of gastric cancer cells. In vivo experiments have confirmed that knocking out EFNA1 can weaken the distant metastasis ability of gastric cancer and provide a target for targeted therapy of gastric cancer [28]. Yamamoto et al. studied and found that EFNA1 may be an effective index to evaluate the prognosis of colorectal cancer, and their cell experiments have also confirmed that knocking down EFNA1 can inhibit tumor proliferation, migration and invasion
[29]. The study by Kandouz et al. also confirmed that the EFN family may reduce the adhesion between cells and lead to metastasis of tumor cells [30]. In this study, 8 ESCA-related cell lines were selected. And EFNA1 expression was detected with $\mathrm{qRT}-\mathrm{PCR}$ and WB at the ESCA cell level. The results showed that the expression of EFNA1 mRNA and proteins was significantly higher in cancer cells than that of normal cells. EFNA1 can highly express in ESCA cells and may play the role of oncogenes. EC-9706 cells with the highest EFNA1 expression and ECA109 cells with low EFNA1 expression were transfected with EFNA1-shRNA1 and EFNA1shRNA2 to construct a cell model with low EFNA1 expression. It was found that EFNA1-shRNA1 group had a particularly significant decrease in EFNA1 expression, so EFNA1-shRNA1 was selected for subsequent experiments. Proliferation experiments were performed in EC9706 and ECA109 cells transfected with EFNA1shRNA1, and the results showed that knocking down EFNA1 can inhibit the proliferation of ESCA cells.

\section{Conclusions}

To sum up, this study found that EFNA1 expression in ESCA tissues is significantly high, which is related to the prognosis of ESCA. It may be an independent risk factor affecting its prognosis, which provides an important basis for clinical evaluation of the prognosis of patients with ESCA. Knocking down EFNA1 can affect the biological process of ESCA cell proliferation at the cell level and is expected to be a new target for ESCA therapy. However, there are limitations in this study. There is no large sample research and no animal experiments. These problems provide directions for future research.

\section{Supplementary Information}

The online version contains supplementary material available at https://doi. org/10.1186/s12957-021-02362-8.

Additional file 1. Nomogram.

Additional file 2. EFNA1 Relationship between expression and ESCA characteristics of clinical parameters.

\section{Acknowledgements}

Not applicable.

Authors' contributions

$Y Z$ and $H R$ conceived and designed the study and drafted the manuscript. $Y Z$, JZ, GP, TG, CZ, AH, and YL collected, analyzed, and interpreted the experimental data. JZ, GP, and $H R$ revised the manuscript for important intellectual content. All authors read and approved the final manuscript.

\section{Funding}

This study is funded by Qiqihar City Science and Technology Plan Project (SFGG-201642).

Availability of data and materials

The datasets used and/or analyzed during the present study are available from the corresponding author on reasonable request. 


\section{Declarations}

\section{Ethics approval and consent to participate}

The study has been approved by the Ethics Committee of The Third Affiliated Hospital of Qiqihar Medical College, with signed written informed consents obtained from the patients and/or their guardians.

\section{Consent for publication}

Not applicable.

\section{Competing interests}

The authors declared no competing interests.

Received: 2 April 2021 Accepted: 5 August 2021

Published online: 16 August 2021

\section{References}

1. Kamangar F, Malekzadeh R, Dawsey SM, Saidi F. Esophageal cancer in Northeastern Iran: a review. Arch Iran Med. 2007:10:70-82.

2. Bray F, Ferlay J, Soerjomataram I, Siegel RL, Torre LA, Jemal A. Global cancer statistics 2018: GLOBOCAN estimates of incidence and mortality worldwide for 36 cancers in 185 countries. CA Cancer J Clin. 2018;68(6):394-424. https://doi.org/10.3322/caac.21492.

3. Cui Y, Chang D, Liu M, Lin C, Zhao B, Zhang X, et al. Identification of exon 19 and 21 mutations of EGFR gene in Chinese patients with esophageal squamous cell carcinoma. World J Surg Oncol. 2013;1 1(1):266. https://doi. org/10.1186/1477-7819-11-266

4. Chen R, Zheng RS, Zhang SW, Zeng HM, Wang SM, Sun KX, et al. Analysis of the incidence and mortality of esophageal cancer in China in 2015. Zhonghua Yu Fang Yi Xue Za Zhi. 2019;53(11):1094-7. https://doi.org/10.3 760/cma.j.jissn.0253-9624.2019.11.004.

5. Maeda N, Shirakawa Y, Tanabe S, Sakurama K, Noma K, Fujiwara T. Skeletal muscle loss in the postoperative acute phase after esophageal cancer surgery as a new prognostic factor. World J Surg Oncol. 2020;18(1):143. https://doi.org/10.1186/s12957-020-01908-6.

6. Himanen JP, Goldgur Y, Miao H, Myshkin E, Guo H, Buck M, et al. Ligand recognition by A-class Ephreceptors: crystal structures of the EphA2 ligandbinding domain and the EphA2/ephrin-A1 complex. EMBO Rep. 2009;10(7): 722-8. https://doi.org/10.1038/embor.2009.91.

7. Kou CJ, Kandpal RP. Differential expression patterns of Eph receptors and ephrin ligands in human cancers. Biomed Res Int. 2018;2018:7390104.

8. Jellinghaus S, Poitz DM, Ende G, et al. Ephrin-A1/EphA4-mediated adhesion of monocytes to endothelial cells. Biochim Biophys Acta. 1833;2013:220121.

9. Alves DS, Westerfield JM, Shi X, Nguyen VP, Stefanski KM, Booth KR, et al. A novel pH-dependent membrane peptide that binds to EphA2 and inhibits cell migration. Elife. 2018;7:e3664.

10. leguchi K, Maru Y. Roles of EphA1/A2 and ephrin-A1 in cancer. Cancer Sci. 2019;110(3):841-8. https://doi.org/10.1111/cas.13942.

11. Ma TT, Wang L, Wang JL, Liu YJ, Chen YC, He HJ, et al. Hypoxia-induced cleavage of soluble ephrinA 1 from cancer cells is mediated by MMP-2 and associates with angiogenesis in oral squamous cell carcinoma. Onco Targets Ther. 2019;12:8491-9. https://doi.org/10.2147/OTT.S213252.

12. Brantley-Sieders DM, Fang WB, Hwang Y, Hicks D, Chen J. Ephrin-A1 facilitates mammary tumor metastasis through an angiogenesis-dependent mechanism mediated by EphA receptor and vascular endothelial growth factor in mice. Cancer Res. 2006;66(21):10315-24. https://doi.org/10.1158/ 0008-5472.CAN-06-1560.

13. Yang PW, Chiang TH, Hsieh CY, Huang YC, Wong LF, Hung MC, et al. The effect of ephrin-A1 on resistance to Photofrin-mediated photodynamic therapy in esophageal squamous cell carcinoma cells. Lasers Med Sci. 2015; 30(9):2353-61. https://doi.org/10.1007/s10103-015-1812-8.

14. Khodayari N, Mohammed KA, Lee H, Kaye F, Nasreen N. MicroRNA-302b targets MCl-1 and inhibits cell proliferation and induces apoptosis in malignant pleural mesothelioma cells. Am J Cancer Res. 2016;6(9):19962009.

15. Miao H, Gale NW, Guo H, Qian J, Petty A, Kaspar J, et al. EphA2 promotes infiltrative invasion of glioma stem cells in vivo through cross-talk with Akt and regulates stem cell properties. Oncogene. 2015;34(5):558-67. https://doi. org/10.1038/onc.2013.590.
16. Nakamura R, Kataoka H, Sato N, Kanamori M, lhara M, Igarashi $\mathrm{H}$, et al. EPHA2/EFNA1 expression in human gastric cancer. Cancer Sci. 2005;96(1): 42-7. https://doi.org/10.1111/j.1349-7006.2005.00007.x.

17. Shi ZZ, Zhang YM, Shang L, Hao JJ, Zhang TT, Wang BS, et al. Genomic profiling of rectal adenoma and carcinoma by array-based comparative genomic hybridization. BMC Med Genomics. 2012;5(1):52. https://doi.org/1 $0.1186 / 1755-8794-5-52$

18. Toma Ml, Erdmann K, Diezel M, Meinhardt M, Zastrow S, Fuessel S, et al. Lack of ephrin receptor A1 is a favorable independent prognostic factor in clear cell renal cell carcinoma. PLoS One. 2014;9(7):e102262. https://doi. org/10.1371/journal.pone.0102262.

19. Chen FF, Zhang SR, Peng H, Chen YZ, Cui XB. Integrative genomics analysis of hub genes and their relationship with prognosis and signaling pathways in esophageal squamous cell carcinoma. Mol Med Rep. 2019;20(4):3649-60. https://doi.org/10.3892/mmr.2019.10608.

20. Zhao M, Huang W, Zou S, Shen Q, Zhu X. A five-genes-based prognostic signature for cervical cancer overall survival prediction. Int J Genomics. 2020;2020:8347639.

21. De Robertis M, Loiacono L, Fusilli C, Poeta ML, Mazza T, Sanchez M, et al. Dysregulation of EGFR pathway in EphA2 cell subpopulation significantly associates with poor prognosis in colorectal cancer. Clin Cancer Res. 2017; 23(1):159-70. https://doi.org/10.1158/1078-0432.CCR-16-0709.

22. Wada H, Yamamoto H, Kim C, Uemura M, Akita H, Tomimaru Y, et al. Association between ephrin-A1 mRNA expression and poor prognosis after hepatectomy to treat hepatocellular carcinoma. Int J Oncol. 2014;45(3): 1051-8. https://doi.org/10.3892/ijo.2014.2519.

23. Zhao S, Yu M. Identification of MMP1 as a potential prognostic biomarker and correlating with immune infiltrates in cervical squamous cell carcinoma. DNA Cell Biol. 2020;39(2):255-72. https://doi.org/10.1089/dna.2019.5129.

24. Simonian M, Mosallaei M, Khosravi S, Salehi R. rs12904 polymorphism in the 3'-untranslated region of ephrin A1 ligand and the risk of sporadic colorectal cancer in the Iranian population. J Cancer Res Ther. 2019;15:15-9.

25. Kitagawa Y, Uno T, Oyama T, Kato K, Kato H, Kawakubo H, et al. Esophageal cancer practice guidelines 2017 edited by the Japan esophageal society: part 2. Esophagus. 2019;16(1):25-43. https://doi.org/10.1007/s10388-0180642-8.

26. Holzman LB, Marks RM, Dixit VM. A novel immediate-early response gene of endothelium is induced by cytokines and encodes a secreted protein. Mol Cell Biol. 1990;10(11):5830-8. https://doi.org/10.1128/mcb.10.11.5830-5838.1 990.

27. Sukka-Ganesh B, Mohammed KA, Kaye F, Goldberg EP, Nasreen N. Ephrin-A1 inhibits NSCLC tumor growth via induction of Cdx-2 a tumor suppressor gene. BMC Cancer. 2012;12(1):309. https://doi.org/10.1186/1471-2407-12-309.

28. Zhuo W, Liu Y, Li S, Guo D, Sun Q, Jin J, et al. Long noncoding RNA GMAN, up-regulated in gastric cancer tissues, is associated with metastasis in patients and promotes translation of ephrin A1 by competitively binding GMAN-AS. Gastroenterology. 2019;156:676-691.e11.

29. Yamamoto H, Tei M, Uemura M, Takemasa I, Uemura Y, Murata K, et al. Ephrin-A1 mRNA is associated with poor prognosis of colorectal cancer. Int J Oncol. 2013:42(2):549-55. https://doi.org/10.3892/ijo.2012.1750.

30. Kandouz M. The Eph/Ephrin family in cancer metastasis: communication at the service of invasion. Cancer Metastasis Rev. 2012;31(1-2):353-73. https:// doi.org/10.1007/s10555-012-9352-1.

\section{Publisher's Note}

Springer Nature remains neutral with regard to jurisdictional claims in published maps and institutional affiliations.

Ready to submit your research? Choose BMC and benefit from:

- fast, convenient online submission

- thorough peer review by experienced researchers in your field

- rapid publication on acceptance

- support for research data, including large and complex data types

- gold Open Access which fosters wider collaboration and increased citations

- maximum visibility for your research: over $100 \mathrm{M}$ website views per year

At BMC, research is always in progress.

Learn more biomedcentral.com/submissions 